\title{
Sitä ei voi ylittää, sitä ei voi alittaa
}

\section{Sanna Karkulehto, Aino-Kaisa Koistinen ja Essi Varis (toim.): Reconfiguring Human, Nonhuman and Posthuman in Literature and Culture. New York: Routledge, 2019, 400 s.}

Sanna Karkulehdon, Aino-Kaisa Koistisen ja Essi Variksen toimittama kokoelma yhdistää 13 artikkelin verran posthumanistisen ajattelun suuntia nykykulttuurin ilmiöihin. Paino on vahvasti kirjallisuudessa, sarjakuvasta visuaalisen runouden kautta perinteisempään muotoon, mutta mukana on myös digitaalista kulttuuria, etnografiaa ja outolintuja. Otsikon ydintermin reconfiguring voisi leikillään kääntää yritykseksi hahmottaa paitsi uudelleen myös yhdessä: yhteisyys ja yhdistelmät ovat kirjan avainsanoja, kuten toisaalta myös välittyneisyys ja kääntäminen. Johdanto kartoittaa tapoja lähestyä inhimillisen ja ei-inhimillisen suhdetta nykykulttuurissa ja erityisesti kirjallisuudentutkimuksessa. Posthumanismin temaattisista perusesittelyistä johdanto poikkeaa paneutuneilla summauksilla kirjallisuustieteellisestä keskustelusta, kuten kognitiivisen kirjallisuustieteen tilasta tai luonnollisen ja epäluonnollisen narratologian kiistasta, joka koskee keskeisesti kysymystä kuvittelukyvyn rajoista: kuinka tiiviisti kertomusmuoto ja kirjallisuus kietoutuvat ihmiskokemukseen? Näitä pohjustuksia perustelee myös monen artikkelin painotus kognitiiviseen narratologiaan.

Kirjan neljästä osiosta ensimmäinen hahmottelee posthumanistisen kirjallisuuden ja lukemisen piirteitä. Post-etuliite voi tunnetusti merkitä sekä jonkin ylittämistä että eteenpäin viemistä, ja jälkeisyyden/jälkeläisyyden jännitteet liittyvät myös posthumanismin hetteikköön. Tähän Carole Guessen artikkeli raivaa hyvää polkua, vaikka halu antaa posthumanistiselle kirjallisuudelle määritelmä tuntuu tarpeettomalta ja yritys hahmottaa ei-inhimillisen lukijan/kirjoittajan mahdollisuutta Jakobsonin viestintämallin kautta on hieman jäykkä. Karoliina Lummaa pohtii ei-inhimillisen jälkiä kokeilevassa nykyrunoudessa. Niin kuin ihmisen perustava eronteko ei-inhimillisestä aina palaa (dekonstruktion hengessä) "kummittelemaan" ihmisen sisällä, posthumanistinen luenta voi pyrkiä "manaamaan" piilostaan taiteen syntyyn osallistuvaa ei-inhimillistä kehollisuutta ja materiaalisuutta. Kaisa Kortekallion artikkeli taas ruotii kognitiivisen kirjallisuudentutkimuksen keinoin fiktioon eläytymisen mahdollisuutta viritellä ympäristötietoisuutta. Immersio minä-kerrontaan ja tuntu tekstin fiktionaalisuudesta eivät, kuten usein on ajateltu, kategorisesti hylji toisiaan vaan voivat yhdistyessään rikastaa luentaa.

Toisessa osiossa "Imagining Aliens and Monsters" Essi Variksen artikkeli tarjoaa selkeän katsauksen ei-inhimillisen kokemuksen paikkaan kognitiivisessa kertomuksentutkimuksessa sekä oivan analyysin Sandman-sarjakuvista: 
muotoaan muuttavat hahmot esiintyvät ihmismäisinä, koska heitä katselee juuri ihmislukija, jonka väistämättä inhimillistävää kognitiota heidän olomuotonsa heijastaa. Sarjakuva tiedostaa samalla ihmisperspektiivin välttämättömyyden ja rajallisuuden, ja tuota rajaa hyödyntävällä outouttamisella nostaa esiin ei-inhimillisten maailmojen rikkauden. Jonne Arjorannan artikkeli, tapaustutkimus ei-inhimillisistä pelattavista hahmoista Aliens vs. Predator -pelissä, tekee hyviä havaintoja ihmiskeskeisyydestä pelisuunnittelussa. Tärkeä huomio on myös peleille tyypillinen vaikeus erottaa apuvälineitä "luonnollisen" ruumiin ja aistihavainnon simuloinnista. Marleena Mustolan ja Sanna Karkulehdon artikkeli kuvaa, kuinka sekä lapset että hirviöt on toiseutettu, kiehtovasti resonoivin tavoin, hegemonisiin normeihin asettuvan aikuisen standardeista. Lastenkirjallisuus tarjoaa huomattavan areenan inhimillisen ja ei-inhimillisen suhteen tarkkailulle ja (uudelleen)rakentamiselle.

Kolmannessa osiossa "Becoming with Animals" Mikko Keskisen artikkeli, joka edustaa perinteisen teksti- ja ihmislähtöistä, kepeän tarkkaa tulkintaa, analysoi Charles Siebertin romaanin Angus koira-minäkertojaa ennen kaikkea ihmiskulttuurin ilmentäjänä. Ei-inhimillisen kokemuksen kääntyminen ihmishavainnolle mielekkääksi on keskeinen ongelma monissa kirjan artikkeleissa, oli kyse sitten hajuaistimuksen visuaalisesta esittämisestä (Aliens vs. Predator) tai kääntämisestä ei-lineaariseksi kerronnaksi (Angus). Brad Bolmanin teksti käynnistyy jäljittämällä sian korostunutta asemaa anatomian historiassa ja päätyy tarkastelemaan alastonperformanssia sikolätissä. Vaikka hierarkiat eivät noin vain taiteessa katoa, avautuu myös haavoittuvuudesta kaltaisuutta, lopulta hyvin toisenlaista kuin yrityksessä ymmärtää ihmistä leikkelemällä sikaa. Hana Porkertová hahmottelee etnografisen tutkimuksen keinoin opaskoiran ja opastettavan muodostamaa kokonaisuutta. Siinä missä Mustolan ja Karkulehdon artikkeli tarttui tapaan, jolla lapset on rajattu normatiivisen aikuis-ihmisyyden ulkopuolelle, Porkertová tarkastelee vammaisuuden suhdetta normiin. Teksti soveltaa Deleuzen ja Guattarin ajattelua koosteisuudesta ja (de)territorialisaatiosta harvinaisen sujuvasti ja selkeästi.

Neljäs osio keskittyy teknologian ja toimijuuden kysymyksiin. Cléo Collomb and Samuel Goyet perkaavat kahtalaista käsitystä tietokoneista ja -järjestelmistä, yhtäältä sieluttomina ja passiivisina työkaluina, toisaalta alustana kaikkivoipuuden fantasioille. Ymmärrämme digitaalisen järjestelmän "sielunelämää" tulkkaamalla sen prosessit samastuttavaan muotoon, samalla yksinkertaistaen ja inhimillistäen sen toimijuutta. Koneiden toimijuus tulee artikkelin mukaan esiin erityisesti silloin, kun toimintaan tulee häiriö, ja saman huomion tekee Marleena Huuhka kiinnostavassa artikkelissaan Minecraft-pelin toimijuuksista. Pelisession kooste muodostuu paitsi ihmispelaajista myös pelin suunnittelijoista, algoritmeista, pelin hahmoista, pikseleistä, ja niin edelleen. Ilmiöt samalle (deleuzelaisen immanenssin) tasolle tuova tulkinta sopii pelitutkimukseen, mutta kovin litteä ontologia uhkaa myös hukata ilmiöiden materiaaliset spesifisyydet ja sen, etteivät eri abstraktiotasoilla elävät kuvaukset tai 
syy-seuraukset aina kohtaa. Patricia Flanagan ja Raune Frankjær puolestaan tekevät puettavaan teknologiaan keskittyvää taiteellista tutkimusta, jota heidän artikkelinsa teoretisoi ja esittelee. Keskiössä on päähine, joka pareissa käytettynä muuntaa toisen käyttäjistä puhetta ohuiden bamburuokojen kahinaksi toiseen päähineeseen. Visio teknologian ja luonnon "kyborgaanisesta" yhtymisestä, joka veisi ihmishavainnon rakenteita kohti ei-inhimillistä, on kiehtovasti kuvattu, vaikka artikkelin harmonista maalailua kannattelee teoriakuorrutteinen tekno-optimismi.

Kirjan päättävät Juha Raipolan "jälkisanat" kannattaa ehkä lukea heti johdannon jälkeen, sillä erinomainen perkaus toimijuuspuheen dynamiikasta auttaa lähestymään monia muista artikkeleista. Keskeinen ongelma Raipolan näkökulmasta on, että miellämme ei-inhimillisen toimijuuden seuraten samaa perinteistä, intentionaalisen ja keskitetyn ihmistoimijuuden mallia, jota posthumanismin (ja sitä ennen antihumanismin pitkine perinteineen) oikeastaan oli tarkoitus kritisoida. Samalla ilmiöiden kompleksiset särmät hioutuvat ihmisenkokoisiksi, simppeleiksi kertomuksiksi. Raipolan voisi sanoa ehdottavan jonkinlaista "negatiivista narratologiaa", jossa materian toimijuus piirtyy esiin vasten aina vain kekseliäämpää kyvyttömyyttämme kertoa siitä adekvaatteja tarinoita.

Posthumanismi sekoittaa ja purkaa perinteisiä jakolinjoja orgaanisen ja koneellisen, subjektin ja materian, ihmisen ja eläimen välillä. Toisaalta kyse on tutkimusalojen uusista kytkennöistä, ja tässä mielessä on sopivaa, että artikkelit lähestyvät kirjan fokusta välillä hyvin eri tavoin ja aineistoin. Kuten Porkertová artikkelissaan toteaa, posthumanistinen lähestymistapa ei tarkoita vain sitä, että ei-inhimilliset toimijat otetaan huomioon, vaan että itse inhimillisen ja ei-inhimillisen kategorinen kaksinapaisuus kyseenalaistuu. Ajatus ihmiskeskeisen asetelman hetkellisestä ja tarpeellisesta horjumisesta jonkinlaisessa kohtaamisessa, kun ei-inhimillinen (melkein) murtautuu inhimillistämisen läpi, on lähes joka artikkelissa toistuva retorinen motiivi. Keskeistä kirjan eetoksessa on, ettei kulttuurituotteiden tarjoamaa ei-inhimillistä näkökulmaa sen enempää naiivisti niellä kuin toisaalta torpata sen mahdollisuutta tutkailla ja törkkiä inhimillisen ja ei-inhimillisen suhdetta. Vaikka kokonaisuus on osin hajanainen, on kiinnostavaa nähdä samojen inhimillistämisen ja vierauden jännitteiden toistuvan ikään kuin spontaanisti, muotoaan muuttaen, artikkelista ja kontekstista toiseen.

Initioimatonta lukijaa voi turhauttaa, ettei kaikkia viittauksia esimerkiksi antihumanismin perinteeseen, "representationalismiin" tai "immanenssin tasoon" avata, mutta nämä ovat poikkeuksia. Turhaa jargonia on vähän ja toimittajien ansioksi voi lukea, että käsitteellisesti raskaammatkin tekstit pitävät paneutuvan lukijan kärryillä. Kokonaisuutena teos tarjoaa hyvän lajitelman nykytutkimuksen posthumanistisia pyrintöjä, sekä sen ei-inhimillisiä säikeitä että auttamattoman inhimillistä sitkoa.

Jouni Teittinen 